\title{
Physiological characteristics of musical theatre performers and the effect on cardiorespiratory demand whilst singing and dancing.
}

\section{Abstract}

Musical Theatre (MT) combines acting, singing and dancing within a performance. The purpose of the current study was two-fold; firstly, to report on the cardiorespiratory fitness of pre-professional MT dancers and secondly, to examine the cardiorespiratory demand of singing whilst dancing. Twenty-one participants ( $F=16, M=5 ; 20 \pm 1.23$ yrs; $169.1 \pm 9.24 \mathrm{~cm} ; 62.7 \pm 10.56 \mathrm{~kg}$ ) in their final year of pre-professional training volunteered for the study. All participants carried a maximal aerobic capacity test on a treadmill using a portable breath-by-breath gas analyser. Nine participants completed a 4-minute section from Chorus Line twice; singing and dancing, and just dancing, in a randomised order whilst wearing the same portable gas analyser. Blood lactate was measured at the end of each trial. Male participants had significantly greater peak oxygen consumption ( $M$ vs. F; 67.6 \pm 2.30 vs. $\left.55.6 \pm 4.42 \mathrm{ml} . \mathrm{kg}^{-1} \cdot \mathrm{min}^{-1}, \mathrm{p}<0.001\right)$ and anaerobic threshold (\% of peak $\mathrm{VO}_{2}$ ) ( $\mathrm{M}$ vs. $\mathrm{F} ; 54.6$ $\pm 4.04 \%$ vs. $43.1 \pm 3.68 \% p<0.001$ ) whilst maximum heart rate and heart rate at anaerobic threshold were similar. The physiological demands of dancing vs. singing+dancing were similar with the exception of the singing+dancing trial having significantly reduced mean breathing frequency and increased lactate $(p<0.01)$. MT dancers' aerobic capacity is greater than that observed in other theatre-based dance genres. The observed breathing frequency and lactate differences in the Chorus-line trails could be due to singing reducing breathing frequency thereby influencing cardiorespiratory recovery mechanics and subsequently blood lactate levels.

Keywords: dance; performance; cardiorespiratory; aerobic capacity; lactate 


\section{Introduction}

Dance is a generic term that covers a wide diversity of genres that have distinct choreographic movements[1] and performance demands[2]. There has been limited research on the cardiorespiratory demands of dance with the majority focusing on classical ballet[3-8] and modern dance[9-12] with a few studies covering other genres such as jazz[13, 14] and street dance[15]. These studies suggested that the studied dance genres were all intermittent in nature though the work to rest ratio and intensity ratios differed between the different genres. Reported data have mainly focused on class $[6,8,10,14,16-18]$ and rehearsals $[6,8,13,17]$ with only a few studies reporting simulated performance[7, 15-17] and one reporting heart rate during stage performance[3]. Early studies were hampered by equipment limitations and often relied on heart rate to extrapolate oxygen demand which later was shown to misrepresent work done[19]. More recent studies benefited from equipment advances and could collect expired gases through portable telemetric gas analysers $[5,6,10,17]$. Significant differences were reported in cardiorespiratory stress between dance class, rehearsals and performance; with the first two environments placing significantly less stress on the body than dance performance.

Cardiorespiratory data (oxygen consumption and heart rate) on dance performance indicated that dancers are exercising close to their maximal cardiorespiratory capacities with a greater stress on the lactate system compared to class and rehearsal[3, $7,12,15]$. Time motion analysis indicates that this is due to differences in the work to rest ratio; performance was generally characterised as having fewer and/or shorter rest periods accompanied by higher work intensities[2].

The genre of Musical Theatre (MT) combines acting, singing and dancing within a performance. Although it was initially theatre-based it has diversified to film and cruise ships potentially employing more dancers worldwide than classical ballet and modern dance. The performance schedule of dancers exceed that of other dance genres with 8 performances a week for 9 to 12 -month contracts 
compared to 125-200 for ballet and contemporary/modern companies [20]. The few scientific or medical studies that have used MT performers as participants focused on injury and eating behaviours. Injury incidence was 0.87 injuries per dancer per year for professional MT dancers with lower extremity injuries accounting for 52\% of all injuries[21]; compared to an injury incidence of 6.8 injuries per dancer per year for classical ballet, though the latter also had the majority of injuries in the lower extremities[22]. Student MT dancers reportedly had poor nutritional knowledge but little disordered eating[23].

The purpose of the current study was two-fold; firstly, to report on the cardiorespiratory fitness of pre-professional MT dancers and secondly, to examine the cardiorespiratory demand of singing whilst dancing. A number of studies have indicated that dancers are exercising very close to their maximum during performance[4, 17]. Musical theatre places an extra stress on the dancer by requiring the dancer to sing either at the same time or during breaks between the dancing therefore effecting recovery.

\section{Methods:}

Volunteers were recruited through advertising posters from an elite single pre-professional musical theatre school in the UK. The college has a $96 \%$ employment rate for graduates entering professional MT jobs. Inclusion criteria included participating fully in their training programme and free from injury in the past 3-months, and in their last year of pre-professional training. Exclusion criteria included compromised training in the past 3-months and being in years 1 or 2 of the training programme.

Nine participants volunteered for the dance and dance+sing aspect of the study and 21 participants for the maximal treadmill test from a cohort of 65 dancers. They did between $35-38$ hours of dance a week, that included self-led rehearsals, and 8 hours of singing and voice classes a week. The study was approved by a university ethics board and all participants signed informed consent. 
Anthropometric data were collected from each participant before exercise started (Table 1). Each participant completed a maximal aerobic capacity test on a treadmill using a portable breath-bybreath gas analyser (Cortex $3 \mathrm{~b}$ Ultra) and Polar heart rate monitor attached to a laptop to allow realtime data analysis. After a 5-minute warm-up on the treadmill, participants started the test at a speed of between $7-10 \mathrm{~km} \cdot \mathrm{h}^{-1}$ that elicited a heart rate of $120 \mathrm{~b} \cdot \mathrm{min}^{-1}$. The speed increased by 1 $\mathrm{km} \cdot \mathrm{h}^{-1}$ every minute until maximal criteria were achieved or the participant ceased the test; the incline was maintained at 0-degrees throughout the test[24]. Maximal termination was implemented when two of the following criteria were met: RER $>1.15$; heart rate $\geq 220$-age; no increase in $\mathrm{O}_{2}$ consumption with increase in workload, RPE 10/10.

Table 1: Participants anthropometric characteristics

\begin{tabular}{r|cccc} 
& Age $(\mathrm{yrs})$ & Height $(\mathrm{cm})$ & Body mass $(\mathrm{kg})$ & BMI \\
\hline All participants & & & & \\
Male $(\mathrm{n}=5)$ & $20 \pm 1.30$ & $182.2 \pm 3.82$ & $78.3 \pm 5.95$ & $23.5 \pm 0.90$ \\
Female $(\mathrm{n}=16)$ & $21 \pm 1.21$ & $164.9 \pm 6.07$ & $57.8 \pm 5.71$ & $21.3 \pm 2.04$ \\
\hline Mance trial participants & & & & \\
Male $(\mathrm{n}=3)$ & $19 \pm 1.53$ & $180.5 \pm 2.78$ & $76.2 \pm 5.95$ & $23.3 \pm 1.12$ \\
Female $(\mathrm{n}=6)$ & $20 \pm 1.17$ & $169.3 \pm 4.64$ & $60.3 \pm 9.25$ & $21.0 \pm 2.86$ \\
\hline
\end{tabular}

On another day, nine final-year students signed informed consent before anthropometric data (table 1) were collected from each participant before exercise started. Each participant completed a 4minute section from Chorus Line twice; singing and dancing, and just dancing in a randomised order. After a warm-up, 10-minutes rehearsing the sequence, dancers were fitted with the same portable breath-by-breath gas analyser (Cortex 3b Ultra) and Polar heart rate monitor. The face mask encompassed the nose and mouth and didn't interfere with the mouth movements required for singing. Blood lactate (Lactate Pro) was taken from the ear at the start and end of each trial. Participant's had a 30-minute rest period between trials to allow recovery and lactate washout (BLa $\left.<1.5 \mathrm{mmol} . \mathrm{L}^{-1}\right)$. 
Data and Statistical analysis:

Dance trials

All cardiorespiratory data underwent a 5-breathe smooth. For the treadmill data, peak $\mathrm{VO}_{2}$ and heart rate were recorded. Anaerobic threshold was calculated using V'e breakpoint and $\mathrm{V}^{\prime} \mathrm{e} / \mathrm{VO}_{2}$ with $\mathrm{V}^{\prime} \mathrm{e} / \mathrm{VCO}_{2}$ methods[25] and the heart rate at that point recorded. Independent t-tests were used to compare male and female data.

Participant's dance trial data were reported as recorded data and as a percentage of the peak treadmill data (relative). Time spent at different oxygen consumption and heart rate bands were calculated for each participant for the both the recorded and relative data. Due to the low number of participants, Mann-Whitney $\mathrm{U}$ tests were used to test the difference between sex (males vs female) and event (dance vs. dance+sing) for the dependent variables (absolute and relative mean oxygen consumption, heart rate, ventilatory equivalent, breathing frequency, METS and blood lactate) using SPSS (version 20). Significance was set at $p \leq 0.01$ in recognition of the low participant numbers.

\section{Results:}

Treadmill data for the participants can be found in table 2; peak oxygen consumption ( $t=-5.769$, $d f=19 ; p<0.001, C l-16.4,-7.67)$ and anaerobic threshold $\left(\%\right.$ of peak $\left.V_{2}\right)(t=-5.953, d f=19 ; p<0.001$, $\mathrm{Cl}-15.51,-7.44)$ were significantly greater for the male participants, whilst maximum heart rate and heart rate at anaerobic threshold were similar.

Table 2: Treadmill cardiorespiratory data for all participants 


\begin{tabular}{r|lllll} 
& $\begin{array}{l}\mathrm{VO}_{2} \text { peak } \\
\left(\mathrm{ml}_{\mathrm{kg}}^{-1} \cdot \mathrm{min}^{-1}\right)\end{array}$ & $\begin{array}{l}\text { Anaerobic } \\
\text { Threshold } \\
\left(\mathrm{ml} \mathrm{kg}^{-1} \cdot \mathrm{min}^{-1}\right)\end{array}$ & $\begin{array}{l}\text { Anaerobic } \\
\text { Threshold } \\
\left(\% \mathrm{VO}_{2} \mathrm{max}\right)\end{array}$ & $\begin{array}{l}\text { HRmax } \\
\left(\mathrm{b} . \mathrm{min}^{-1}\right)\end{array}$ & $\begin{array}{l}\text { Anaerobic } \\
\text { Threshold } \\
\left(\mathrm{b} \cdot \mathrm{min}^{-1}\right)\end{array}$ \\
\hline All participants & & & & & \\
Male $(\mathrm{n}=5)$ & $67.6 \pm 2.30$ & $54.6 \pm 4.04$ & $80.7 \pm 4.21$ & $196 \pm 4.47$ & $164 \pm 9.94$ \\
Female $(\mathrm{n}=16)$ & $55.6 \pm 4.43$ & $43.1 \pm 3.69$ & $77.8 \pm 5.63$ & $195 \pm 5.65$ & $166 \pm 9.52$ \\
\hline Dance trial participants & & & & & \\
Male $(\mathrm{n}=3)$ & $67.3 \pm 1.15$ & $53.6 \pm 4.51$ & $79.6 \pm 5.52$ & $198 \pm 3.32$ & $160 \pm 6.35$ \\
Female $(\mathrm{n}=6)$ & $57.4 \pm 1.82$ & $42.6 \pm 3.44$ & $74.3 \pm 7.22$ & $196 \pm 9.36$ & $168 \pm 14.36$ \\
\hline
\end{tabular}

Analysis of the dance+sing vs dance data reported no significant difference between the sexes for any of the dependent variables. Statistical differences were reported for breathing frequency $(U=12$, $p=0.04 ; C l=0.5,11.8)$, trial end lactate $(U=6.0, p=0.007 ; C l-3.4,-0.9)$ and change in lactate (pre-post trial) $(U=4.5, p=0.006 ; C l-3.4,-0.9)$. In the dance+sing trial breathing frequency was significantly lower and blood lactate significantly greater than the dance alone trial (Table 3).

Table 3: Absolute and relative mean physiological data for the dance and dance+sing trials

\begin{tabular}{|c|c|c|c|c|}
\hline & Sex & Dance & Dance+Sing & Difference \\
\hline Oxygen consumption & $M$ & $34.9 \pm 5.39$ & $35.7 \pm 5.89$ & $1.0 \pm 5.76$ \\
\hline$\left(\mathrm{ml} \cdot \mathrm{kg}^{-1} \cdot \mathrm{min}^{-1}\right)$ & $\mathrm{F}$ & $29.3 \pm 7.11$ & $32.2 \pm 5.81$ & $3.0 \pm 4.82$ \\
\hline Oxygen consumption & $M$ & $51.9 \pm 8.11$ & $52.9 \pm 8.05$ & $1.0 \pm 8.61$ \\
\hline (\% $\mathrm{VO}_{2}$ peak) & $\mathrm{F}$ & $51.3 \pm 13.34$ & $56.5 \pm 10.89$ & $5.2 \pm 8.38$ \\
\hline Heart rate & $M$ & $155 \pm 19.40$ & $152 \pm 15.89$ & $-3 \pm 22.99$ \\
\hline (b. $\min ^{-1}$ ) & $\mathrm{F}$ & $168 \pm 14.62$ & $172 \pm 7.83$ & $3 \pm 10.36$ \\
\hline Heart rate & $M$ & $77.2 \pm 9.65$ & $75.6 \pm 7.91$ & $-2 \pm 11.44$ \\
\hline$\left(\% \mathrm{HR}_{\max }\right)$ & $\mathrm{F}$ & $83.7 \pm 7.27$ & $85.5 \pm 3.89$ & $1 \pm 5.12$ \\
\hline Mean ventilation & $M$ & $79.3 \pm 25.14$ & $73.3 \pm 15.01$ & $-5.9 \pm 20.93$ \\
\hline$\left(1 . \min ^{-1}\right)$ & $\mathrm{F}$ & $60.7 \pm 5.47$ & $65.3 \pm 13.29$ & $4.5 \pm 15.86$ \\
\hline Breathing Frequency & $M$ & $51.9 \pm 0.55+$ & $42.8 \pm 1.12 \dagger$ & $-9.1 \pm 1.53$ \\
\hline (bf.min $\min ^{-1}$ ) & $\mathrm{F}$ & $54.5 \pm 3.42+$ & $45.9 \pm 4.41 \dagger$ & $-5.5 \pm 7.83$ \\
\hline METS & $M$ & $10.8 \pm 2.81$ & $10.9 \pm 2.61$ & $0.1 \pm 2.19$ \\
\hline
\end{tabular}




\begin{tabular}{lc|l|l|l} 
& $\mathrm{F}$ & $8.8 \pm 2.51$ & $9.9 \pm 2.43$ & $1.1 \pm 1.49$ \\
\hline Blood lactate & $\mathrm{M}$ & $4.9 \pm 0.25^{\dagger}$ & $6.4 \pm 0.45^{\dagger}$ & $1.4 \pm 0.41$ \\
$\left(\mathrm{mmol} . \mathrm{I}^{-1}\right)$ & $\mathrm{F}$ & $4.8 \pm 2.69 \dagger$ & $7.2 \pm 2.79 \dagger$ & $2.7 \pm 1.94$ \\
\hline $\begin{array}{l}\text { Blood lactate change } \\
\left(\mathrm{mmol} . \mathrm{I}^{-1}\right)\end{array}$ & $\mathrm{M}$ & $3.6 \pm 0.12^{\dagger}$ & $5.1 \pm 0.51^{\dagger}$ & $1.5 \pm 0.55$ \\
& $\mathrm{~F}$ & $2.7 \pm 1.1{ }^{\dagger}$ & $5.4 \pm 2.25^{\dagger}$ & $2.7 \pm 1.98$ \\
\hline
\end{tabular}

†significant difference $p<0.01$

Figure 1: Mean time spent in different oxygen consumption bands during the dance and dance+sing trials

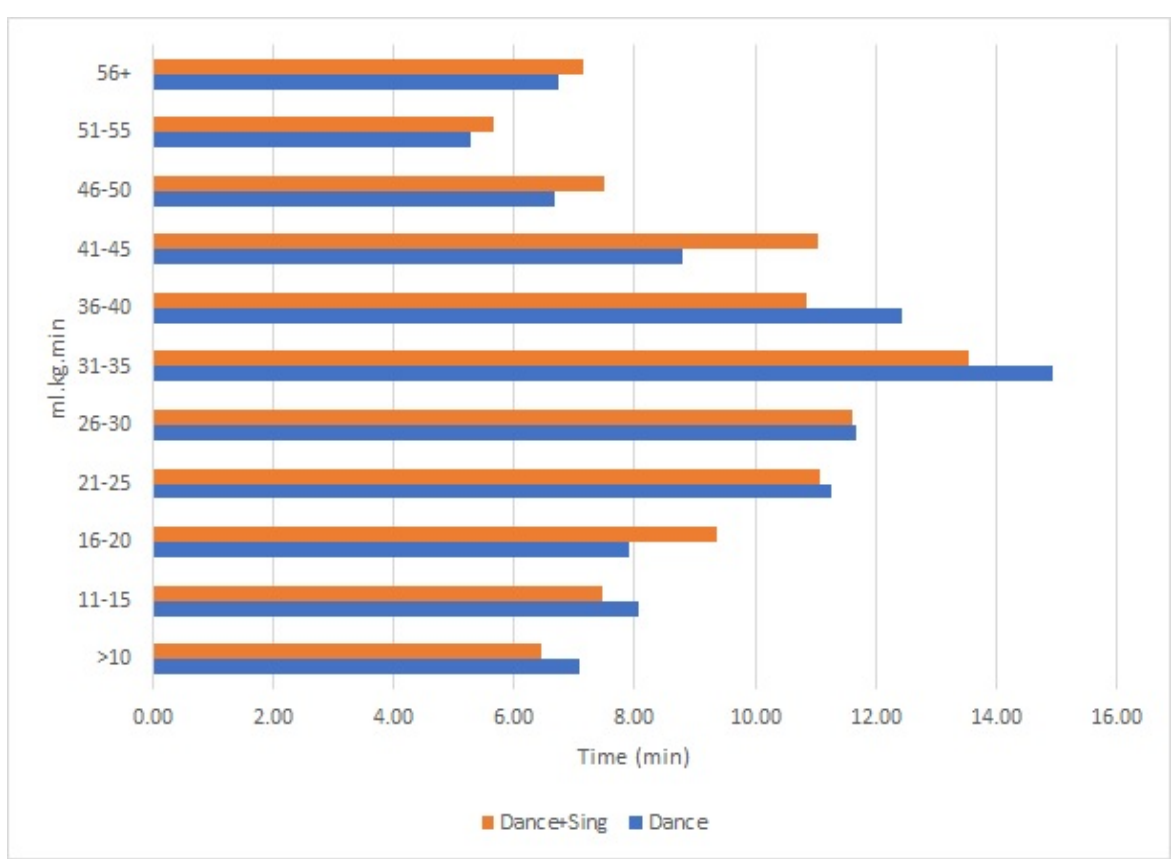

There were no significant main effects or within-subject effects for oxygen consumption and heart rate banding. Figures 1 and 2 indicate some non-significant trends; for instance, time spent in the oxygen consumption bands above $41 \mathrm{ml} \cdot \mathrm{kg}^{-1} \cdot \mathrm{min}^{-1}$ was greater in the dance+sing trials than the dance trials. Participants spent more time between $161-190$ b. min $^{-1}$ and below 120 b. min $^{-1}$ in the dance+sing trials than the dance trials, though the later trial spent more time between 141-150 b. $\min ^{-1}$. 
Figure 2: Mean time spent in different heart rate bands during the dance and dance+sing trials

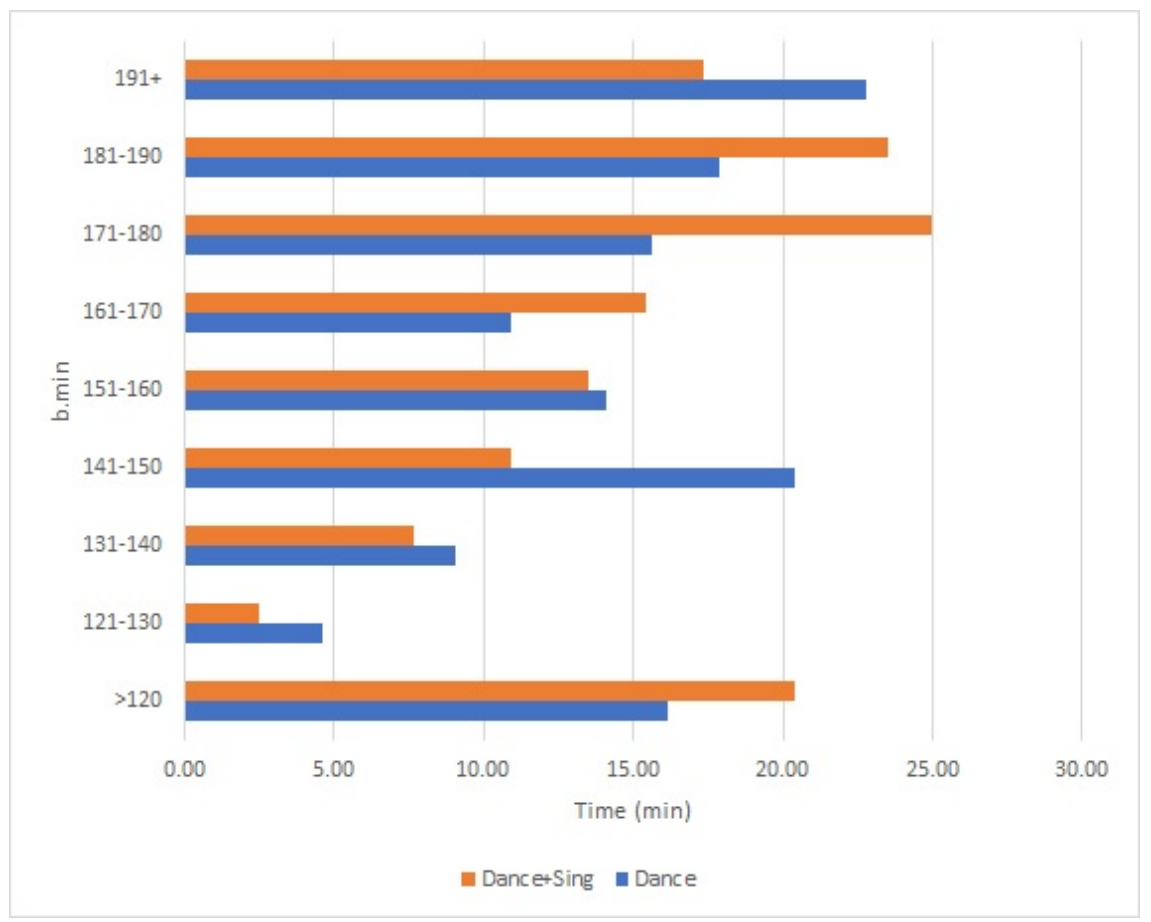

\section{Discussion}

Through a cross-sectional design the current study has provided the first physiological data on musical theatre performers. The cardiorespiratory profiles of musical theatre performers indicated aerobic fitness levels higher than that previous reported for other dance theatre genres $[4,5,7,26$, 27] and similar to hip hop dancers [15] . The anaerobic threshold (AT) for MT dancers was similar to that reported for classical ballet principal and artist dancers [27]. Wyon et al proposed [27] the increased AT was due to longer work rest ratios during performance for those positions[28] that caused the AT to move to the right on the oxygen consumption curve[25]. The current study cannot extrapolate the potential reasons why MT dancers are more aerobically fit that their counterparts in other dance genres as longitudinal data are required. Potentially, the intense performance and training schedule in MT could provide the stimuli for the observed adaptation but until there are more data on this genre this is supposition.

Comparison with previous dance performance data are not possible as in the present study we only measured a short excerpt (4 minutes) of the full performance. The focus was on whether concurrent 
singing increased the physiological demands of a musical theatre dance routine compared to dancing alone. Oxygen and heart rate data indicate no significant difference between the two trials, but significant differences were noted for breathing frequency and blood lactate. We propose that the two are linked. The singing can occur whilst dancing but mainly happens in the lulls between dancing. Therefore the reduced breathing frequency seen within the dance+sing trial is due to the singing component reducing breathing frequency in these dance breaks. This subsequently has an effect on recovery mechanics with compromised breathing frequency reducing oxygen delivery to the recovering muscles compared to the dance only trial. This means that replenishment of ATP within the muscle cells is reduced, potentially leading to greater use of the anaerobic glycolysis during work periods $[29,30]$. Thereby leading to the observed increased levels of blood lactate in the dance+sing trials.

Choreographers should be aware that the combination of singing and dancing can compromise metabolic recovery dynamics and could negatively affect (though increased blood lactate) subsequent dance sequences[31]. Over a prolonged performance this could lead to reduced dance intensity and/ or compromised movement and/or singing. Choreographically, lead singers have simplified dance repertoire so that their singing is not compromised but the chorus line choreography maintains its complexity and therefore is potentially vulnerable to compromised movement quality.

The generalisability of the current data to the wider MT community is limited due to the low participant numbers and recruiting from one locale. The cardiorespiratory fitness data have provided an insight into the physiological fitness of pre-professional MT performers but not how this was achieved whether it is initial selection onto the course, the training on the course or supplemental training carried out by the participants. The participants were all in their final year of study and approximately $20 \%$ had already completed professional contracts, taking time out from their 
training. The data from the dance vs dance+sing trials provide initial sight into the demands that these performers have to cope with, but they require greater diversity and duration of the actual performances analysed to provide generalisability.

In conclusion, musical theatre performers' cardiorespiratory fitness profiles indicate they have greater maximal aerobic capacities than previously published data on dancers from other dance theatre genres. The singing component of musical theatre reduces breathing frequency during the breaks between dance sequences. This has a negative effect on the physiological recovery from the dance sections thereby increasing lactate levels. This consequence could negatively affect the quality of singing or dancing as the dancer would need to decide to either compromise the singing component to improve breathing frequency and reduce lactate levels or decrease the intensity of the dance sequences so that the singing component is affected by the breathing frequency.

\section{References}

1. Copeland, R. and M. Cohen, eds. What is dance? 1983, Oxford University Press: Oxford.

2. Wyon, M., E. Twitchett, M. Angioi, F. Clarke, G. Metsios, and Y. Koutedakis, Time motion and video analysis of classical ballet and contemporary dance performance. Int J Sports Med, 2011. 32(11): p. 851-855. 10.1055/s-0031-1279718

3. Cohen, J., K. Segal, and W. McArdle, Heart rate response to ballet stage performance. The Physician and Sportsmedicine, 1982. 10(11): p. 120-133.

4. Cohen, J.L., K.R. Segal, I. Witriol, and W.D. McArdle, Cardiorespiratory responses to ballet exercise and $\mathrm{VO}_{2 \max }$ of elite ballet dancers. Med Sci Sports Exerc, 1982. 14(3): p. 212-217.

5. Rodrigues-Krause, J., G. dos Santos Cunha, C. Alberton, B. Follmer, M. Krause, and A. Reischak-Oliveira, Oxygen consumption and heart rate responses to isolated ballet exercise sets. Journal of Dance Medicine and Science, 2014. 18(3): p. 99-105.

6. Rodrigues-Krause, J., M. Krause, G.d.S. Cunha, D. Perin, J.B. Martins, C.L. Alberton, M.I. Schaun, P.I.H. De Bittencourt Jr, and A. Reischak-Oliveira, Ballet dancers cardiorespiratory, oxidative and muscle damage responses to classes and rehearsals. Eur J Sports Sci, 2014. 14(3): p. 199-208.

7. Schantz, P. and P.-O. Astrand, Physiological characteristics of classical ballet. Med Sci Sports Exerc, 1984. 16(5): p. 472-476.

8. Rimmer, J.H., D. Jay, and S.A. Plowman, Physiological characteristics of trained dancers and intensity level of ballet class and rehearsal. Impulse, 1994. 2: p. 97-105. 
9. Beck, S., M. Wyon, and E. Redding, Changes in energy demand of dance activity and cardiorespiratory fitness during one year of vocational contemporary dance training. J Strength Cond Res, 2018. 32(3): p. 841-848. 10.1519/JSC.0000000000002357

10. Wyon, M., A. Head, C. Sharp, and E. Redding, The cardiorespiratory responses to modern dance classes: differences between university, graduate, and professional classes. J Dance Med Sci, 2002. 6(2): p. 41-45.

11. Wyon, M. and E. Redding, The physiological monitoring of cardiorespiratory adaptations during rehearsal and performance of contemporary dance. J Strength Cond Res, 2005. 19(3): p. 611-614.

12. Wyon, M.A., G. Abt, E. Redding, A. Head, N. Craig, and C. Sharp, Oxygen uptake during modern dance class, rehearsal, and performance. J Strength Cond Res, 2004

13. Galanti, A., M. Holland, G. Shafranski, P. Loy, S. Vincent, W. Heng, and M. K., Physiological Effects of Training for a Jazz Dance Performance. The Journal of Strength \& Conditioning Research, 1993. 7(4): p. 206-210.

14. Lavoie, J.M. and R.M. Lebe-Neron, Physiological effects of training in professional and recreational jazz dancers. J Sports Med, 1982. 22: p. 231-236.

15. Wyon, M., J. Harris, F. Adams, R. Cloak, F. Clarke, and J. Bryant, Cardiorespiratory profile and performance demands of elite hip-hop dancers: Breaking and New Style. Medical Problems in Performing Artists, 2018. 33(3): p. 198-204. https://doi.org/10.21091/mppa.2018.3028

16. Baillie, Y., M. Wyon, and A. Head, Highland Dance: heart rate and blood lactate differences between competition and class. Inter J Sports Physiol Perf, 2007. 2(4): p. 371-376. 10.1123/ijspp.2.4.371

17. Wyon, M., G. Abt, E. Redding, A. Head, and N. Sharp, Oxygen uptake during of modern dance class, rehearsal and performance. J Strength Cond Res, 2004. 18(3): p. 646-649. 10.1519/13082.1

18. Dahlstrom, M., J. Inasio, E. Jansson, and L. Kaijer, Physical fitness and physical effort in dancers: a comparison of four major dance styles. Impulse, 1996. 4: p. 193-209.

19. Redding, E., M. Wyon, J. Shearman, and L. Doggart, Validity of using heart rate as a predictor of oxygen consumption in dance. Journal of Dance Medicine and Science, 2004. 8(3): p. 6972.

20. Laws, H., Newgate Press

21. Evans, R.W., R.I. Evans, and S. Carvajal, Survey of injuries among West End performers. Occup Environ Med, 1998. 55(9): p. 585-593.

22. Allen, N., A. Nevill, J. Brooks, Y. Koutedakis, and M. Wyon, Ballet injuries: injury incidence and severity over 1 year. J Orthop Sports Phys Ther, 2012. 42(9): p. 781-90. 10.2519/jospt.2012.3893

23. Vitzthum, K., E. Endres, F. Koch, D.A. Groneberg, D. Quarcoo, E. Wanke, and S. Mache, Eating behavior and nutrition knowledge among musical theatre students. Med Probl Perform Art, 2013. 28(1): p. 19-23.

24. Wyon, M., in Sport and Exercise Physiology Testing Guidelines: British Association of Sport and Exercise Science Testing Guidelines. Routledge, Taylor and Francis Group ^2007 p. 249262.

25. Wasserman, K., J. Hansen, D. Sue, B. Whipp, and R. Casaburi, Lea \& Febiger

26. Rimmer, J.H., J. Rosentsweig, and B. Rubal. Physiological profile of trained female dance majors. in American Alliance for Health, Physical Education, Recreation and Dance. 1981. Boston.

27. Wyon, M., N. Allen, R. Cloak, S. Beck, P. Davies, and F. Clarke, Assessment of maximum aerobic capacity and anaerobic threshold of elite ballet dancers. Medical Problems in Performing Artists, 2016. 31(3): p. 145-149.

28. Twitchett, E., M. Angioi, Y. Koutedakis, and M. Wyon, Video analysis of classical ballet performance. Journal of Dance Medicine and Science, 2009. 13(4): p. 124-8. 
29. Bangsbo, J. and B. Saltin, in Intermittent High Intensity Exercise: Preparation, Stresses and Damage Limitations. E and FN SPON^^1993 p. 49-69.

30. Yamamoto, Y., Y. Takei, Y. Mutoh, and M. Miyashita, Delayed appearance of blood lactate with reduced frequency breathing during exercise. Eur J Appl Physiol, 1988. 57(4): p. 462466.

31. Forestier, N. and V. Nougier, The effects of muscular fatigue on the coordination of a multijoint movement in human. Neurosci Lett, 1998. 252(3): p. 187-190. 